\title{
Okay girl, it's up to you": a case study of the use of a Seizure Alert Dog to improve the wellbeing of a student with epilepsy
}

\author{
Sarah Plowman \\ Honours Student, School of Education \\ James Cook University, Cairns, Australia
}

\author{
Dr Peter Boman \\ School of Learning and Professional Studies \\ Queensland University of Technology, Brisbane, Australia
}

\author{
David Williams \\ School of Education, University of South Australia \\ Adelaide, Australia
}

\begin{abstract}
The relationship between student well-being and the other vital outcomes of schooling is unequivocal. Improved outcomes in all aspects of student wellbeing are positively associated with improved outcomes in all other aspects of schooling. This educational imperative only serves to strengthen and support the moral imperative for schools and schooling to be inclusive, supportive, and nurturing in order to maintain and support student well-being. (Fraillon 2005, p. 12)
\end{abstract}

\section{Introduction}

This paper reports unique insights into the influence of a Seizure Alert Dog on a middle-years student's wellbeing and his family, social and school relationships. It does this by examining his and his mother's experiences with and perceptions of his circumstances during the period of change instigated by the introduction of the Seizure Alert Dog. Although there is documentation about the behaviours exhibited 
by Seizure Alert Dogs in warning their owners of an impending seizure, there appears to be no research into the nature or consequences of the broader relationship between the dogs and their owners. The research reported here seeks to redress this situation by examining the narrative of the change in the student's wellbeing.

\section{Wellbeing}

According to Masters (2004, p. 2)

Schools have always seen it as part of their role to support and encourage children's all-round development, including their cognitive, interpersonal, social, aesthetic, physical, and moral/spiritual growth. Beyond the academic, schools have been committed to children's general wellbeing: in seeing children develop into wellrounded, healthy individuals who can take their place as informed, principled and engaged members of society. In fulfilling this role, schools have worked alongside and complemented families, churches and other institutions in the community.

Wellbeing encompasses the holistic welfare of students and, according to Fraillon (2005, p. 8), five dimensions of this are consistently identified in the literature - physical, social, psychological, cognitive and economic. However, the literature also includes frequent reference to other significant dimensions such as spiritual and emotional. Regardless of minor variations in detail, there is unequivocal evidence that wellbeing is integral rather than incidental to school performance (Catholic Education Office 2006).

Hill (2004, p. 17) couches the concept of wellbeing in the context of processes of support and provision of opportunity for individuals, rather than in terms of outcomes:

We are not prescribing what this person should become; we are just seeking to ensure that as far as possible his or her choices are not disabled by physical, mental, or socioeconomic deficits ... Our job is simply to maximise their life chances.

While schools undoubtedly have a major role to play in this process, they do so by working alongside and complementing other institutions of society, particularly the family. The focus of this case study is the improvement in wellbeing of a young adolescent who is a middle-years student with epilepsy) and his family following the introduction of a Seizure Alert Dog.

\section{Epilepsy and Seizure Alert Dogs}

Epilepsy Action Australia (2008) explains epilepsy as:

a disruption of the normal electrochemical activity of the brain that results in seizures. Under certain circumstances anyone can have a seizure. It is only when there is a tendency to have recurrent seizures (more than one) that epilepsy is diagnosed.

Although all seizures occur as the result of a sudden disturbance in the brain, the seizures may present differently. Sufferers might have short periods of partialconsciousness during which they appear simply to stand and stare (complex partial/absent seizures/petit mal), or they might undergo longer periods of 
unconsciousness during which they might collapse and convulse (tonic-clonic/grand mal).

Because seizures can occur for a large number of reasons and because of diagnostic and reporting anomalies, the prevalence of epilepsy in Australia is not definitively established. However, the accepted guide is that approximately $1-2 \%$ of Australians have epilepsy (Epilepsy Action Australia 2008). People may be diagnosed with epilepsy at any time during their lifetime, and the condition appears not to be linked to age, race, or ethnicity.

If seizures are not managed successfully they can have a dramatic, adverse influence on relationships, independence, quality of life, employment opportunities and social mobility, and individuals can be exposed to serious injury. Established ways of managing epilepsy include combinations of surgery, diet, electronic impulses and anti-convulsant drugs. However, more recently, the use of dogs as companions for people with epilepsy has been introduced as an aid.

Dogs are believed to be the most reliable domesticated animals, capable of being trained to aid people with disabilities (Serpell, Coppinger \& Fine 2000). 'Assistance Dogs' (dogs trained specifically to assist people with disabilities) provide a range of services for adults and children in the form of animal-assisted therapy.

Although epilepsy is not officially categorised as a disability, Seizure Alert Dogs (SADs) are being used increasingly to assist people with epilepsy. SADs have the specific function of alerting people with epilepsy to an imminent seizure, thus giving sufficient warning of the need to stop what they are doing and take protective action (Ormerod et al. 2005). Ortiz and Liporace (2005, paragraph 2) report that "the interest in 'seizure-alert dogs' arose in the 1980s when a woman with epilepsy said that her dog could predict her seizures". In a more clinical trial, Duncan and Allen (2000, p. 308) selected a woman to receive a service dog "to manage the interference in her life that the seizures caused”. The dog's early detection of seizures minimised injury to the woman and allowed her to participate in the work force. She considered the dog to be the solution to her maintaining a 'normal' life.

Although it is unresolved as to whether dogs can be trained to alert their owners about pending seizures, there is some research evidence to indicate that dogs can be deliberately trained to recognize specific changes in their owner preceding a seizure (Dalziel et al. 2003; Strong, Brown \& Walker 1999). When this occurs, the dog alerts the owner through behaviour such as anxious type barking, pawing, whining or intent staring (Dalziel et al. 2003; Mott 2004).

\section{Case Study background}

A case study is a qualitative approach adopted by the researcher to examine an individual, a development, an occurrence, or an activity. Stake (2000, p. 443) implies that "[c]ase study is not a methodological choice but a choice of what was to be studied”. Therefore, case studies are a strategy of inquiry used when both a phenomenon, and the context in which the phenomenon resides, need to be explored 
to explain influences on that phenomenon (Yin 1993). Despite their limitations, case studies can allow for some generalisations to be drawn from a particular example to something of broader concern (Blaxter, Hughes \& Tight 2001).

The type of case study reported here was a singular case study - one which focuses on a particular event or circumstance (Hird 2003; Stake 2000). In this case the focus was on the wellbeing of a middle-school student with epilepsy and of his mother. This research approach was chosen specifically to explore the participants' emic perspectives - reality as constructed by the participants (Gall, Gall \& Borg 2005). This case was also an intrinsic case study as it stands alone with in its particularity as the focus of interest. The researcher's role in the intrinsic case study is to encourage the eliciting of the stories by those who are, as Stake (2000, p. 445) put it, "living the case". These insights disclose the nature of their realities (Gall et al. 2005).

The Association of Australian Assistance Dogs (ASDOGS) played a lead role in the identification and recruitment of the two key participants in this case study. A mother with an adolescent son who had epilepsy and was the owner of a SAD agreed to participate in the study. The intention of this type of purposive sampling is "to select individuals for case study who are likely to be 'information-rich' with respect to the researchers’ purposes” (Gall et al 2005, p. 309).

The son (pseudonym Simon) is 13 years old and lives with his mother, father and brother in Queensland. He is the youngest family member and was diagnosed with epilepsy (tonic-clonic), when he was three years old. He takes medication to help manage his seizures which are triggered by overtiredness, heat exposure, overactivity and stress. He has had his SAD for one year and has passed a public access test allowing him to go into public places with his SAD. He has been able to attend school with his SAD since the beginning of 2006. He has not had a tonic-clonic seizure since receiving the dog. He has also been diagnosed with Attention Deficit Disorder (ADD) and is considered by his school to be two years behind in his level of academic development.

The mother (pseudonym Mary) lives with her husband and her two sons. She maintains the SAD's general health and wellbeing. As Simon has resided with his mother all of his life, she was considered a primary source of information, as interviewing adolescents can pose a number of possible hazards (Breakwell 2000). For example, they may be unwilling to assert themselves; they may feel inferior to the adult interviewing them; they may answer to be agreeable; or they may respond with 'don't knows'.

The primary method of data collection was one face-to-face interview with Simon and two with Mary over a two-day period. The interviews were conducted in the family home and were audio recorded. The interview schedules consisted of a series of open-ended questions which encouraged the interviewees to provide more information rather than a 'yes' or 'no' answer (Wilkinson \& Birmingham 2003). This approach is designed to induce specific answers (Fraenkel \& Wallen 2003). Patton's (1990) six basic types of research questions were used to guide the 
interview: background or demographic; knowledge; emotional based; opinion value; feeling; and sensory questions.

A funnelling technique was developed in which the general background enquiries were asked first while the feeling and sensory questions were last ones. This approach allowed the participants to settle into the interview, and to feel comfortable responding to the questions (Wilkinson \& Birmingham 2003). This ultimately generated the 'insiders' perspective of the events (Lankshear \& Knobel 2004).

The interviews were analysed using categorical analysis (Lankshear \& Knobel 2004). The interview responses were transcribed into written texts (transcripts), in preparation for analysis into datasets. To expedite analysis, the responses were numbered sequentially by respondent and utterance.

The text was then cross-checked with themes that related to the literature (Gall et al. 2005; Lankshear \& Knobel 2004). Categories which emerged from the data, such as the supportive relationship between the SAD and Mary and Simon, were systematically colour coded (Punch 2005). The categories developed the initial themes, giving a continuously changing representation of what is present in the data (Richards 2005).

The results of the categorical analysis are presented in three pivotal categories. The first category describes living with epilepsy from the perspectives of Mary and Simon. The second category describes the supportive relationship between the SAD and Simon. The third category depicts the influence of the SAD on Simon's wellbeing at home and school.

\section{Category 1: Life around epilepsy}

Simon had suffered from tonic-clonic epilepsy since he was three years old, although, at the time of the interviews, he had not experienced a seizure for two years. Mary described the seizures as "very unpredictable" and typically exhibited in Simon losing consciousness, having a full fit, wetting himself, and then regaining consciousness. He could recall no warning of an imminent seizure except for a vague, dizzy feeling. Mary described these earlier seizures as: "full on panic for everyone. For my son it was disappointment, hurt and embarrassment”.

Mary recalled that, at the period during which Simon's epilepsy had been most active, living with the condition stretched her ability to cope. "Everything was just based on him. Everything was centred on him, and everything was around the epilepsy ... It seemed to rule our life.” Mary and Simon shared an inseparable bond but their relationship was constantly defined by the ever-present possibility of an emergency. Consequently, Mary felt the need to advise everyone of Simon's epilepsy. She believed that it was her responsibility as the adult to do this.

Simon is now thirteen years old. Mary is aware of the likelihood that if a seizure occurs after the age of eleven, then the child will grow into adulthood with 
epilepsy. At the time of this research, there was no certainty whether, for Simon, the epilepsy would stop during adolescence or continue into adulthood.

Most of Simon's seizures occurred at school. As a result, he felt insecure about going to school. Mary also felt insecure at home as she literally waited by the phone in the event of an emergency. Mary stated that when the seizures happened:

My husband and myself would hurt for him. We would be upset because it would throw him back on medication or higher doses of medication, and because it was tonic-clonic ... it has always been full on.

The seizures at school concerned Mary because she was not there to assist Simon. If he experienced a seizure in the playground, Simon had to pick himself up and go to the office and report the event.

Simon's last tonic-clonic seizure occurred when he was eleven. He was returning home from the shops with a friend on a hot day. He just dropped to the ground and his friend did not know what to do. However, a passing teacher recognised Simon and called the ambulance. The impact of the seizure was emphasised in Simon telling Mary: “Mum, I'm never going out again by myself. I'm staying home from now on. I don't ever want that to happen again”. This seizure also affected Mary emotionally. She was particularly upset at the impact on Simon and she feared that he would become reclusive. Indeed, Mary confirmed that this did happen and reported that Simon became very dependent on his life at home with her.

Mary described the impact of epilepsy on Simon's social development. She stated that "he doesn't form friendships well or maintain them for long periods of time”. When Simon went to stay at other people's places, he had to take his medication with him and she had to ensure that all the medical and emergency procedures were known. Mary acknowledged that some people were uneasy about having Simon to stay and that she was also uneasy about his visits. Mary believed that people were scared of the condition and the responsibility that comes with it. Consequently, Simon had been ostracised and isolated because of his epilepsy.

\section{Category 2: The support of a Seizure Alert Dog}

As a reaction to Simon's last seizure and his response of withdrawing, Mary applied for a SAD to support Simon. Although the main reason for receiving the dog was to alert Simon of an imminent seizure, it also encouraged him to feel more confident, safer, and aware that if another seizure were to happen, the dog would be there. He would never again be in the situation where he would be alone without any source of comfort.

Mary reported that their initial period with the dog proved to be stressful because the dog was not fully trained. "We weren’t ready for it ... the dog was trying to tell us some things that we couldn't pick up on and we were trying to train the dog ourselves and we couldn't”. However, subsequently, the dog completed a further period of training and returned fully trained. The change in it was dramatic. It was 
markedly more obedient and reliable. Simon summarised the difference in saying "now the dog does what I say".

The training process concluded with a formal assessment in a public place. Simon and the dog had to demonstrate that they could work together as a team. They were assessed on how the dog responded to Simon's commands and they had to show that they were bonded. Bonding is not regarded as complete until the dog can pick up on Simon's routines, activities, feelings, anxieties and/or anything unusual about him. The dog can be trained to respond to commands and events but Mary believes that the dog cannot necessarily be trained to alert. She believes that it depends on the bond with Simon.

Mary soon came to realise that public education about SADs is limited. She mentioned that, as part of the training process, they were informed "to tell people to please not to pat the dog when she is working - when she is out in public with my son”. The dog knew that when it was wearing its orange jacket, it was working. On one occasion at a shopping centre, a woman tried to pat the dog and when it barked, she became offended. Mary explained that the dog's reaction was its way of telling the woman that it was working and that patting it would distract it from doing its job of ensuring Simon's safety. The need for this public awareness was emphasised and there were certainly ramifications for Simon's school life.

At the school level, prior to Simon acquiring the dog, the teachers knew what to do when they saw Simon having a seizure. The initial process of managing the involvement of the dog in the school required many negotiations, conferences, and readjustments for all concerned. Although the process began with a classroom focus, ultimately it had to broaden to the school community level. This involved the participation of relevant education department personnel, all the school staff and students, the school bus driver, and children from different schools who shared the same bus.

This process included knowing what the SAD did, why the dog was there, what to do when a seizure happened, and how to receive and respond to the dog working in the school environment. It also incorporated developing plans to keep the dog close to Simon even when health and safety issues were present as in the home economics, woodwork and metalwork rooms. The dog was not allowed to enter these rooms for safety and hygiene reasons, but it was allowed to be at the doorway from where it could monitor Simon. He had to occupy positions in the classes so that he could be close to the dog.

\section{Category 3: The influence of the Seizure Alert Dog}

Mary reported that an article was written in the local paper about Simon and the dog, and a story also appeared on two of the local television channels. Initially, Simon felt rather intimidated by the glare of such publicity, but his self-perception and social confidence soon become much more positive as he realised that people at the school were aware of his situation and more understanding of his circumstances. He soon found that he was making more friends, interacting socially and being more 
accepted in the community. His feeling of belonging and his sense of self-worth increased dramatically as a direct consequence of the dog's presence in his life.

In terms of Simon's home life, Mary stated that the introduction of the SAD meant that "[h]e has got a friend and it is his best friend". Mary illustrated the closeness of the bond between Simon and the SAD: "They sleep face to face and one or the other will have a hand or paw over the other. It is really wonderful to see and very loving”. In addition, Mary revealed how the nature of a simple act such as going to the toilet or using the bathroom had improved since the SAD had been acquired. For the first time, Simon had a level of personal privacy and an increased sense of independence in basic functions because the SAD could accompany him. Previously, he had to leave the door open in case he had a seizure.

Simon reported feeling much more confident and independent at home since he had the dog in his life and Mary now allows him to be at home by himself. In keeping with Strong, Brown, Huyton and Coyle's (2002) finding that having a SAD reduced the seizure frequency, Simon has not had a tonic-clonic seizure since receiving the dog. While this research does not claim proof of any causal relationship in this case study, it can report on Mary's perceptions of the situation, particularly through a critical incident, as follows.

Mary witnessed an episode in which Simon approached her saying that he felt dizzy and yet he felt that something was different. He lay down on his bed with the dog beside him and Mary deliberately did not intervene but stayed in her room. After a short time, the dog left Simon and moved to Mary's room, putting its paw on her bed and stared intently at her. So Mary accompanied the dog to Simon's room. As they entered, Simon stood up, walked around the bed three times and then lay down and went to sleep. The dog sat down beside him and put its paw on him. Although it appeared that Simon had suffered some form of seizure, Mary described it as being much more benign than usual and more like 'sleep walking'. As a result of this event, Mary was convinced that it was the bonding between the dog and Simon that had calmed him when he felt the dizziness, and which had then led to the seizure being so much less traumatic in nature than previous episodes. Mary speculated whether Simon's relationship with the dog reduced his anxiety to a level where he did not go into a full seizure. Mary has admitted to being amazed at how the dog continuously supports Simon and at how much he trusts the dog.

Mary also reported that this relationship had reduced pressure on the whole family and improved the quality of family life. Now, when Simon goes to school, he is relaxed and so is Mary. She reflected on the changes in her wellbeing since the dog came into Simon's life:

I don't sit beside the phone waiting for it to ring. I feel completely comforted that the dog will take care of it. The dog will be there if he has a fit and comes out of it. Before it was always me, me, me. I can feel I can let go now. I can let go as a parent. The dog has taken over my job. She can do all the worrying and support and the comforting. I walk out the door now and say 'Ok, it's up to you'. I have grown to trust the dog. 
The arrival of the SAD has been the catalyst for change in the everyday lives and wellbeing of Mary and Simon. This case study supports Levinson's 1960s finding that a dog's presence helped a child feel a greater sense of security while in therapy (Barker 1999). Simon exhibited this same sense of security while in his dog's presence as it enabled him to feel more confident, more secure and more in charge of his own life. The arrival of the SAD has not only provided him with a 'best friend': it has developed his acceptance of himself and his condition, and has improved his sense of wellbeing to the point that he now goes out by himself, is leading much more of a 'normal life' and is experiencing vastly-improved wellbeing at home, at school and in the community. Hart, Hart and Bergin (1987) noted that the presence of a dog could result in higher self-esteem and more independence for the person it aids, and this has certainly proved to be so in Simon's case.

He has also engaged in more spontaneous social interaction through having the dog. In keeping with research which demonstrated how a dog can fulfil the role of a social agent in that it can have a therapeutic effect on more than one person, Messent (cited in Hart et al. 1987) found that walking dogs in the park increased the likelihood of people engaging in chance conversations. Simon's experience corroborates this finding, as each new encounter reinforces and extends his sense of social competence and belonging.

The therapeutic value of the dog alone can provide benefits for the person. Strong and Brown (2000) confirmed that having the dog will not stop seizures, but it may take away some of the stresses of the seizure and offer a person an opportunity to live an independent life, and this is so in the case of Simon. What is more, the benefits are not restricted to Simon. The SAD has greatly improved Mary's quality of life and has spread to the family as a whole. She has been able to let go as a parent and delegate much of the responsibility of Simon's safety to him and his dog. In Mary’s words, “Okay, girl it’s up to you”.

This study is limited by the size and nature of the purposive sample. It is also acknowledged that the majority of information and insight was provided by Mary. This constrains the ability to generalise from the data, even though case studies can allow some generalisations (Blaxter et al. 2001). That is, because of the absence of previous research in the area, the insights gained into the lives of Mary and Simon can still have application beyond the immediate case study.

There has been no investigation of Simon's school performance since the introduction of the SAD. Rather, this research has concentrated on the socioemotional impact on Simon's wellbeing. It is hoped that this narrative might be a catalyst for the promotion of more understanding and de-stigmatisation of epilepsy, of the potential benefits of Seizure Alert Dogs beyond their core function, and of some steps that schools can take to improve belonging, engagement and wellbeing of students with epilepsy. 


\section{References}

Barker, SB 1999, 'Therapeutic aspects of the human companion animal interaction', Psychiatric Times, vol. XVI, no. 2, viewed 26 May 2006, <http://www.psychiatrictimes.com./p990243.html>.

Blaxter, L, Hughes, C \& Tight, M 2001, How to research, $2^{\text {nd }}$ edn, Open University Press, Buckingham.

Breakwell, GM 2000, 'Interviewing', in Research methods in psychology, $2^{\text {nd }}$ edn, eds. GM Breakwell, S Hammond \& C Fife-Schaw, Sage Publications, London, pp. 240-241.

Catholic Education Office, Archdiocese of Melbourne 2006, Student wellbeing: central to learning and school improvement, Catholic Education Office, Melbourne.

Dalzeil, DJ, Uthman, BM, McGorray, SP \& Reep, RL 2003, 'Seizure-alert dogs: a review and preliminary study’, Seizure, vol. 12, no. 2, pp. 115-120.

Department of Education and Children's Services, South Australia 2005, Statement of Directions 2005-2010, Working Paper, DECS, Adelaide.

Duncan, SL \& Allen, K 2000, 'Service animals and their roles in enhancing independence, quality of life, and employment for people with disabilities', in Handbook on animal-assisted therapy: theoretical foundations and guidelines for practice, ed. AH Fine, Academic Press, San Diego, California, pp. 303-323.

Epilepsy Action Australia 2008, viewed 22 September 2008, <http://www.epilepsy.org.au/epilepsy_explained2.asp\#1>.

Fraenkel, JR \& Wallen, NE 2003, 'Observation and interviewing', in How to design and evaluate research in education, $5^{\text {th }}$ edn, McGraw Hill, New York, pp. 455-463.

Fraillon, J 2005, Measuring student well-being in the context of Australian schooling, Discussion Paper, Curriculum Corporation (MCEETYA), Carlton South, Victoria.

Gall, JP, Gall, MD \& Borg, WR 2005, 'Case studies in qualitative research', in Applying educational research. A practical guide, $5^{\text {th }}$ edn, Pearson Education, Boston, pp. 304-334.

Hart, LA, Hart, BL \& Bergin, B 1987, 'Socialising effects of service dogs for people with disabilities’, Anthrozoös, vol. 1, no. 1, pp. 41-44. 
Hill, B 2004, 'Core values in the balance', in Proceedings of the ACER Conference 'Supporting Student Wellbeing', 24-26 October, Australian Council for Educational Research, Camberwell, Victoria, pp. 17-20.

Hird, MJ 2003, 'Case study', in The A-Z of social research, eds RL Millier \& JD Brewer, Sage Publications, London, pp. 22-24.

Lankshear, C \& Knobel, M 2004, 'Analysing spoken data in qualitative teacher research', in Teacher research. From design to implementation, Open University Press, Maidenhead, pp. 265-300.

Masters, G 2004, 'Conceptualising and researching student wellbeing', in Proceedings of the ACER Conference 'Supporting Student Wellbeing', 2426 October, Australian Council for Educational Research, Camberwell, Victoria, pp. 1-7.

Mott, M 2004, 'Seizure-alert dogs save humans with early warnings', viewed 12 October 2006,

$<\underline{\text { http://news.nationalgeographic.com/news/2003/04/0416_030416_seizuredo }}$ gs.html>.

Ormerod, EJ, Edney, TB, Foster, SJ \& Whyam, MC 2005, 'Therapeutic applications of the human-companion animal bond', The Veterinary Record, vol. 157, pp. 689-691.

Ortiz, R. \& Liporace, J 2005, “'Seizure-alert dogs”: observations from an impatient video/EEG unit’, Epilepsy and Behaviour, vol. 6, no. 4, pp. 620-622.

Patton, MQ 1990, Qualitative evaluation and research methods, Sage Publications, Newbury Park, CA.

Punch, KF 2005, Introduction to social research, Sage Publications, London.

Richards, L 2005, Handling qualitative data: a practical guide, Sage Publications, London.

Serpell, JA, Coppinger, R \& Fine, AH 2000, 'The welfare of assistance and therapy animals: an ethical comment', in Handbook of animal-assisted therapy: theoretical foundations and guidelines for practice, Academic Press, San Diego, pp. 415-431.

Stake, RE 2000, 'Qualitative case studies', in The sage handbook of qualitative research, eds NK Denzin \& YS Lincoln, $3^{\text {rd }}$ edn, Sage Publications, London, pp. 443-446.

Strong, V \& Brown, SW 2000, 'Should people with epilepsy have untrained dogs as pets?’, Seizure, vol. 9, no. 6, pp. 427-430. 
Strong, V, Brown, SW \& Walker, R 1999, 'Seizure alert dogs - fact or fiction?', Seizure, vol. 8, no. 1, pp. 62-65.

Strong, V, Brown, SW, Huyton, M \& Coyle, H 2002, 'Effect of trained Seizure Alert Dogs ${ }^{\circledR}$ on frequency of tonic-clonic seizures', Seizure, vol. 11, no. 6, pp. 402-405.

Wilkinson, D \& Birmingham, P 2003, 'Interviews', in Using research instruments: a guide for researchers, Routledge Falmer, London, pp. 43-65.

Yin, RK 1993, Applications of case study research, Sage Publications, Thousand Oaks, California. 